\title{
Grain Growth Control of Dielectric and Magnetic Ceramics
}

\author{
Kyoung-Seok Moon ${ }^{\dagger}$ \\ School of Materials Science and Engineering, Gyeongsang National University \\ Jinju, Gyeongnam 52828, Republic of Korea \\ 유전 및 자성 세라믹스에서 입자성장 제어

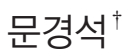 \\ 경상국립대학교 나노 · 신소재공학부
}

(Received August 10, 2021; Revised August 20, 2021; Accepted August 23, 2021)

\begin{abstract}
s
The sintering process transported the atoms in the materials by decreasing the total interface energy. The microstructure changes as a result of grain growth and densification under the capillary driving force due to the interface curvature among grains. The grain growth rate is expressed as the product of the interface mobility and the driving force. According to grain growth theories, the mobility of the interface governed by diffusion control is constant but interface mobility is nonlinear when the movement of an interface is governed by interface reaction. As the growth rate is nonlinear for the regime of interface reaction control, the grain growth is nonstationary with annealing time. The microstructure can be controlled by changing the growth rate of an individual grain with the correlation between the maximum driving force and the critical driving force for appreciable growth. The present paper discusses applications of the principle in the fabrication of dielectric and magnetic ceramic materials.
\end{abstract}

Keywords: Grain growth, Microstructure, Nonstationary grain growth, Dielectric, Magnetic

†Corresponding Author: ksky.moon@gnu.ac.kr 


\section{1. 서론}

일반적으로 세라믹재료는 열처리 공정을 거치며, 열 역학적으로 전체의 에너지, 특히 전체계면에너지를 감 소하는 방향으로 얻어진다. 즉, 전체의 계면 면적을 줄 이고자 입자성장이 일어나며, 분말 성형체 상태의 고체/ 기체 계면이 고체/고체 계면 (입계, grain boundary), 또는 고체와 기체 사이에 액상이 채워지면서 고체/액체 의 계면으로 전환되면서 치밀화가 일어나게 된다. 일반 적으로 고체/기체의 계면에너지보다, 고체/고체의 계 면에너지가 더 낮기 때문에 열처리 동안 치밀화가 일어 날 수 있다. ${ }^{1)}$ 고체/액체의 계면 에너지의 경우, 고체/고 체의 계면에너지보다 낮은 경우 고체와 고체 사이에 액 상이 침투될 수 있고, 그렇지 않은 경우 입자의 삼중점 에 액상이 모인 형태가 될 수 있다. 이렇게 세라믹 재료 의 소결 중에는 계면의 종류를 파악하는 게 매우 중요하 다. 전체 에너지를 감소시키는 방향과, 국부적인 압력 차이에 의해 결국 입자 간의 물질 이동이 일어나게 되는 데, 이 때 계면은 물질 원천 (source)가 되고 ${ }^{1)}$ 이동의 귀 착지 (sink)도 되며, 이동 속도를 제어하는 중요한 인자 가 된다. 세라믹 재료의 물리적 특성 및 기계적 특성은 소결 후 미세구조와 상당히 밀접한 관계가 있다. 미세구 조를 설계하고 디자인하기 위해서는 계면구조의 변화와 이동 현상을 이해하고 그에 따라 미세구조가 구현되는 원리를 이해하는 것이 매우 중요하다. ${ }^{1,2)}$

다결정체에서 입자성장은 작은 입자는 녹고, 큰 입자 는 성장하는 Ostwald ripening 현상으로 일어나고, 현 상학적으로 정상입자성장과 비정상입자성장으로 구분 하고 있다. ${ }^{1)}$ 본 논문에서는 두 현상으로 나뉘어지는 원 리 및 이유를 2차원 핵생성과 입자성장의 이론, ${ }^{1-6)}$ 에 바 탕을 두고 알아보고, 이를 유전 세라믹스 및 자성 세라 믹스에 응용한 예를 살펴보았다. 입자성장 현상은 평형 입자모양 및 계면의 원자구조와 상당한 연관성이 있기 때문에 본 논문에서는 먼저 평형입자모양에 대해 다루 었다. 입자크기분포에 따른 성장구동력의 분포와, 열역 학적 변수에 따른 임계성장구동력과의 관계로 미세구조 제어하는 전략에 대해 간단히 설명하였다. 특히, 기존의
정상(正常)입자성장 (normal grain growth)과 비정상 (非正常)입자성장 (abnormal grain growth)을 각각 정 상(定常)입자성장 (stationary grain growth)과 비정상 (非定常)입자성장 (nonstationary grain growth)으로 표현하는 것이 더 현실적이라는 것을 논의할 예정이다.

\section{2. 본론}

\section{1. 평형입자모양 (Equilibrium Crystal Shape)}

모든 결정들은 열역학적 평형상태에서 특정한 모양, 즉 평형입자모양 (Equilibrium Crystal Shape)을 갖는 다. ${ }^{1,7)}$ 다결정체로 된 세라믹스 내에서는 작은 입자는 소멸하고 큰 입자는 성장하게 되어 소멸하는 입자는 수 축모양 (shrinkage shape)을 하고 성장하는 입자는 성 장모양 (growth shape) ${ }^{1)}$ 을 나타내며, 입자 간의 충돌 또한 입자 모양에 영향을 줄 수 있다. 그러므로, 광학현 미경 혹은 주사전자현미경의 수준에서 미세구조를 관찰 할 때 평형입자모양보다 속도론적 (kinetic)으로 나타난 형태가 쉽게 관찰된다.

결정체의 경우, 평형입자모양은 결정면에 따른 계면에 너지 $\left(\gamma_{i}, A_{i}\right.$ 결정면에서의 계면에너지)가 다르기 때문에 다면체로 나타난다. 평형입자모양은 다음 식 (1)의 계의 전체 계의 에너지를 최소화하려는 형태로 형성된다. ${ }^{1,7)}$

$$
\sum_{i=1}^{N} \gamma_{i} A_{i}
$$

여기서, $\gamma_{i}$ 는 결정면의 단위 면적당 계면에너지이며, $A_{i}$ 는 그 면적이다. 이는 $\gamma-$ plot과 Wulff 정리 (Wullf Theorem) $)^{7}$ 로 잘 알려져 있다. 그림 1은 결정면에 따른 계면에너지를 중심 $\mathrm{O}$ 에서부터 나타내어 $\gamma$-plot (polar diagram)을 결정하고, 중심 $\mathrm{O}$ 에서 $\gamma$-plot 상의 한점을 연결한 선과의 수직면 (Wulff plane)을 만들었을 때 최 소의 Wulff 면으로 둘러싸인 형태가 바로 평형입자모양 이 된다. ${ }^{7)} \mathrm{Wulff}$ 정리에서 중심에서부터 계면이 멀어질 수록 그 계면에너지가 커진다는 것을 알 수 있다.1, 7) 그 림 1에서보면, $\gamma-$ plot에서 계면에너지가 최소인 두 곡선 이 만나는 뾰족한 부분의 cusp이 존재하면 편평한 면이 


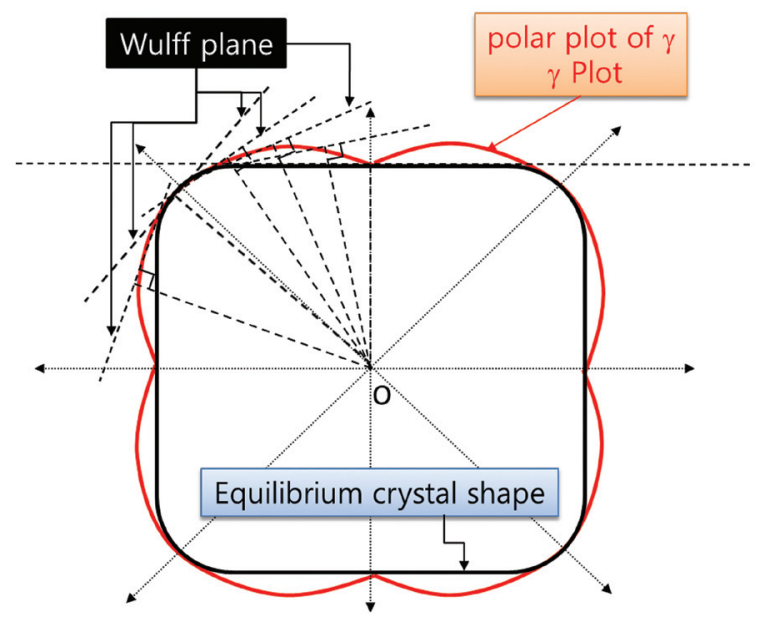

Fig. 1. Schematic showing the Equilibrium Crystal Shape according Wulff construction with polar plot of surface energy $\gamma$

나타나고, 계면에너지가 최대인 선이나 cusp이 존재하 면 평형입자모양에서 꼭지점이나 변이 나타나게 된다. 만약, 계면에너지가 결정방위에 상관없이 모두 같은 등 방적이라면, 평형입자모양은 구 (sphere)가 된다. 입자 성장은 계면의 이동속도와 밀접하다. 계면의 이동속도 는 계면에너지가 클수록 빠르기 때문에, 입자가 성장할 때의 모양은 속도가 느린 면들로 나타나며 대부분 계면 에너지가 낮은 면들로 나타나고, 반대로 수축하는 입자 들의 수축모양은 대부분 결정면의 용해속도가 빠른 면 들로 나타난다.

\section{2. 입자성장 (Grain growth) 이론}

입자성장은 현상적으로 볼 때 대부분의 입자들이 균 일하게 성장하여 평균입자 크기 대비 상대크기의 분 포가 시간이 지남에 따라 변하지 않는 정상 입자성장 (normal grain growth) $^{1,8-10)}$ 과 일부의 입자들만 크게 성장하는 비정상 입자성장(abnormal grain growth) $1,5,9,11-17)$ 으로 분류해왔다. 입자성장 양상을 정확히 구 분하기 위해서는 시간에 따른 변화를 관찰해야한다. 즉, 어떤 하나의 소결 시간에 관찰된 그 입자크기 분포가 균 일하고 일부 예외적으로 큰 입자가 존재하지 않는 계라
고 하더라도 정상 입자성장 거동이라고 단언할 수 없다. 이에 대해서 다음 절에서 계속 논의하겠다.

입자성장은 입자크기에 따른 입자 내부의 압력 차이 및 용해도의 차이에 의한 Ostwald ripening 현상에 의 해 작은 입자는 녹고, 큰 입자는 성장하게 된다. 입자 내 부의 압력 차이는 Young-Laplace 식으로, 표면에서의 증기압과 관련된 용해도의 차이는 Gibbs-Thompson 식으로 설명할 수 있다. 이는 재료의 소결 현상 관련된 책 ${ }^{1)}$ 이나 재료의 열역학 교재 ${ }^{7)}$ 및 물리화학 교재 ${ }^{18)}$ 등에 서 잘 다루고 있다. 입자 내부의 압력 및 용해도는 모두 계면의 곡률과 관련되며 입자의 크기가 작을수록 계면 의 곡률이 커지고, 이 때 입자 내부의 압력이 증가하고, 용해도도 증가하므로, 작은 입자가 녹고 큰 입자로 물질 이 이동하게 되어 큰 입자는 성장하게 된다. 즉, 압력이 높은 작은 입자에서 큰 입자로 물질이 이동하게 되는 것 이다. 소결 중에는 열역학적으로 계의 전체 에너지를 감 소시키는 방향으로 물질 이동을 통해 입자성장과 치밀 화가 이루어지게 되고, 치밀화가 일어나며 입자 내부의 물질이 이동하기 위해서는 물질은 한 입자의 계면에서 부터 다른 입자의 계면으로 이동하게 된다. 작은 입자의 계면에서 원자 입자가 계면 반응 (interface reaction) 에 의해 용해 (dissolution)되어 입자 사이의 액상, 기상 등을 통해 확산 (diffusion)되고, 큰 입자의 계면에서 계 면 반응을 통해 흡착된다. 이렇게 계면 반응 - 확산 계면 반응의 과정이 직렬 관계 (serial process)로 계면 반응과 확산 과정 중 느린 과정이 속도를 결정하게 되는 율속 관계에 있다. ${ }^{6}$

그러므로, 계면 구조와 입자성장 거동은 매우 밀접한 관련이 있다. ${ }^{3-6,12,16,19-36)}$ 계면에서의 원자 흡착을 위 해 필요한 에너지가 없는 경우, 입자성장은 핵생성과정 에서 체적 변화에 의한 에너지변화와 표면 에너지 변화 에 의한 에너지 변화를 고려하여 핵생성 후 입자가 성장 하고, ${ }^{7}, 37$ 확산 과정만 고려하면 된다. 계면에 원자 흡 착이 용이한 kink 밀도가 높다면, 확산되어 계면에 도 착하는 원자들이 연속적으로 흡착될 수 있다. ${ }^{1,38)}$ 그렇 기 때문에, 계면 반응이 없고 확산에 의해 속도가 결정 되는 경우, 입자성장 구동력과 입자성장 속도는 선형 비 


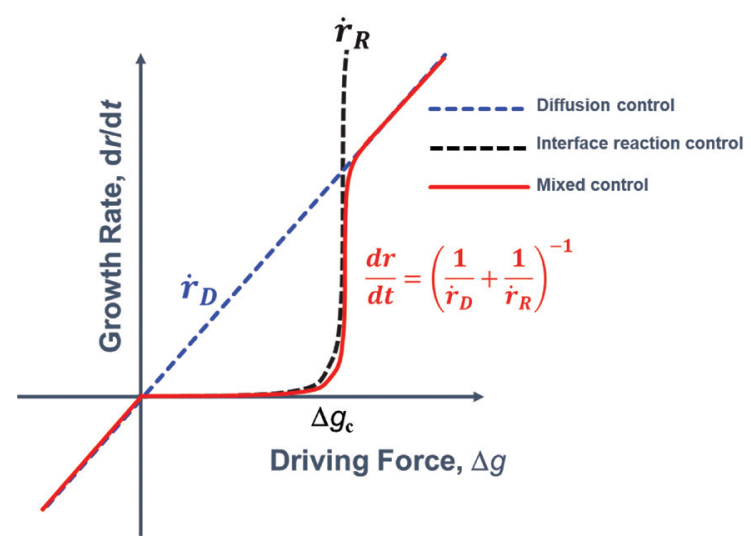

Fig. 2. Schematic showing the growth rate of a crystal as a function of the driving force for diffusion (dashed line), interface reaction (dotted line), and mixed control (solid line).

례 관계를 가지게 된다. ${ }^{6}$ 이처럼 계면 이동 속도가 입 자성장 구동력에 비례할 때, Lifshitz와 Slyozov은 전 체 입자가 고르게 자라는 정상 입자성장이 일어남을 수 식적으로 보였다. 한편, 계면 구조와는 별개로 모세관력 (capillary force)에 의한 입자성장 구동력 $(\Delta g)$ 을 다음 과 같이 Young-Laplace 식으로 설명할 수 있다. 즉, 크기가 $2 r$ ( $r$ 은 반경이다)인 입자의 성장구동력은 다음 식 (2)와 같다. ${ }^{1)}$

$$
\Delta g\left(r, r^{*} ; t\right)=2 \gamma V_{m}\left(\frac{1}{r^{*}}-\frac{1}{r}\right)
$$

여기서, $\gamma$ 는 앞에서도 말한 계면 에너지, $V_{m}$ 은 몰부 피 (molar volume), $r$ 는 입자가 성장하지도 수축하지 도 않을 때의 입자 반경, 즉 임계입자의 반경 (critical size)이다. 이 식 (2)로부터 성장구동력은 입자 크기와 관련 있으며, 임계입자의 크기가 커질수록 감소하고, 입 자크기 분포도에서 가장 큰 입자는 성장구동력이 가장 크게 되는 최대성장구동력 $\left(\Delta g_{\max }\right)$ 을 갖게 된다. 일반적 으로, 임계입자의 경향이 평균 입자크기의 경향이 비슷 하여, ${ }^{39)}$ 대부분 임계입자의 크기를 평균입자크기로 보고 계산하는 경우가 많다. 즉, 평균입자크기가 증가할수록 성장구동력은 감소한다는 것을 알 수 있다. 또 $\mathrm{Ardell}^{10)}$ 은 다결정체에서 액상 기지의 양에 따라 입자성장 구동
력과 입자성장 속도와의 관계에 대해서도 수식적으로 유도하여 확산에 의해 속도가 결정되는 입자성장 속도 $\left(\dot{r}_{D}\right)$ 를 다음과 같이 도출하였다.

$$
\dot{r}_{D} \equiv \frac{d r}{d t}=\frac{A}{r}\left(\frac{1}{r^{*}}-\frac{1}{r}\right) \cdot\left(1+\beta(\theta) \frac{r}{r^{*}}\right)
$$

여기서, $A$ 는 확산속도에 의존하는 상수이고 $\beta(\theta)$ 는 고상 입자의 부피 분율 $(\theta)$ 의 함수이다. 이 식을 이용해 서 입자성장 구동력과 입자성장 속도와의 관계는 그림 2에서 파란색 점선으로 나타난 선형 비례 관계가 된다 (diffusion control), 항상 원점을 지나고, 액상량이 증 가하게 되거나, 확산을 방해하는 인자가 증가하는 경우 그 기울기가 감소하게 된다.

확산 속도에 상관없이 계면 반응이 성장의 속도를 지 배하는 경우는, 계면에 kink 등의 원자 흡착이 용이한 자리가 없는 경우가 된다. 이 때는 2 차원 핵생성 (2D nucleation)에 의해 형성된 2차원의 step에 원자가 흡 착되어 step의 성장으로 이루어진다. ${ }^{1,3-6)}$ 이 때의 계면 반응이 지배적인 입자성장 속도 $\left(\dot{r}_{R}\right)$ 는 다음과 같이 나 타낼 수 있다. ${ }^{6)}$

$$
\dot{r}_{R}=\frac{d r}{d t}=B \exp \left(-\frac{\Delta g^{*}}{k T}\right)=B \exp \left(-\frac{\pi \sigma^{2}}{k T h \Delta g}\right)
$$

여기서, $B$ 는 온도와 물질에 의존하는 상수로 임계 크 기의 핵 근처에 원자 입자가 있을 확률, 원자 입자가 활 성화 에너지를 극복하고 점핑하는 확률 등과 관련된 상 수이다. $k$ 와 $T$ 는 볼츠만 상수와 절대 온도이다. 이 식 에서 중요한 $\Delta g^{*}$ 는 핵이 성장하기 위한 임계 핵생성 에 너지가 되고, 이는 2 차원 핵이 생성될 때 증가하는 표면 에너지와 감소하는 체적 변화에 의한 에너지 변화로 결 정되는 전체 에너지 변화의 최대값이 되는 것으로 그 이 하가 되면 핵이 사라지게 되고, 그 이상이 되면 성장하 게 된다. 이는 step의 높이 $(h)$, 한 step을 만들기 위해 필요한 step free energy $(\sigma)$, 입자 성장구동력 $(\Delta g)$ 과 관련 있는 인자가 되고 다음과 같으며 식 (4)에 적용되 


\section{특 집 ㅁㅃ 문경석}

었다. ${ }^{6)}$

$$
\Delta g^{*}=\frac{\pi \sigma^{2}}{h \Delta g}
$$

식 (4)에서 입자성장 속도 $\left(\dot{r}_{R}\right)$ 와 성장구동력 $(\Delta g)$ 은 지수 함수에 비례하는 비선형적인 관계에 있고, 그림 2 에서 검은색 점선으로 나타난다. 그림 2에서 검은색 점 선의 그래프를 보면 성장이 거의 일어나지 않는 영역과 어떤 특정점 $\left(\Delta g_{c}\right)$ 을 지나면 급격히 증가하는 영역이 생 기는 것을 알 수 있다. 이 특정점을 임계성장구동력이라 부르고, ${ }^{1,40)}$ 이는 식 (4)로부터 소결 온도 (T)가 증가할 수록 감소하고, step free energy가 증가할수록 증가하 며 다음과 같은 관계를 얻을 수 있다 (식 (6)).

$$
\Delta g_{c} \propto \frac{\sigma^{2}}{T}
$$

식 (4)와 (6)에서 계면 반응이 지배적인 경우, 임계성 장구동력 $\left(\Delta g_{c}\right)$ 을 이해 해야하며, 식 (2)로 나타낸 성장 구동력 $(\Delta g)$ 과의 관계에 대해 반드시 살펴보아야 한다. 특히, 임계성장구동력을 극복하는지 못하는지를 판단하 는 것이 중요하므로 앞서 설명한 가장 큰 입자가 갖는 최대성장구동력 $\left(\Delta g_{\max }\right)$ 과의 관계에 대해 파악할 필요 가 있다.

확산이 지배적인 경우와, 계면 반응이 지배적인 경우 각각에 대해 성장구동력 $(\Delta g)$ 과 성장속도 $(d r / d t)$ 와의 관계에 대해 알아보았다. 앞서 설명했듯이 소결 중에 입 자성장은 계면반응-확산-계면 반응의 직렬관계에 의 해 이루어지므로 결국, 느린 과정이 전체 속도를 결정하 는 율속관계에 의해 전체 입자성장 속도는 다음과 같이 mixed control kinetics ${ }^{1}$ 로 나타낼 수 있다.

$$
\frac{d r}{d t}=\left(\frac{1}{\dot{r_{D}}}+\frac{1}{\dot{r_{R}}}\right)^{-1}
$$

식 (3),(4),(7)에 의해 성장구동력에 따른 전체 성장속 도는 결국 그림 2 에서 빨간색 선의관계로 나타나게 된
다. 성장구동력이 작을 경우, 2 차원 핵생성이 느리게 일 어나서 성장속도가 2 차원 핵생성에 의해 정해지고, 성 장구동력이 클 경우는 2 차원 핵생성에 의한 속도가 급 격히 증가하여 성장 속도가 원자의 확산 속도에 의해 서 결정될 것이다. 식 (2)에서 성장구동력은 입자크기 와 관련 있고, 다결정체에서 입자크기는 분포를 갖게 되 므로, 성장구동력 또한 유사한 성장구동력 분포를 갖게 된다. 이 때 최대성장구동력이 임계성장구동력보다 작 은 경우 $\left(\Delta g_{\max }\left\langle\Delta g_{c}\right)\right.$, 모든 입자들은 거의 성장하지 않 게 된다. 반면 최대성장구동력이 매우 크고 대부분 입 자들의 성장구동력이 임계성장구동력보다 훨씬 큰 경우 $\left(\Delta g_{\max } \gg \Delta g_{c}\right)$, 대부분 입자들은 성장할 수 있게 되고, 정상입자성장과 유사한 성장을 할 수 있다. ${ }^{16)}$ 한편, 최 대성장구동력이 임계성장구동력보다 큰 경우 $\left(\Delta g_{\max }\right)$ $\left.\Delta g_{c}\right)$, 일부 입자만 성장할 수 있고, 대부분의 입자는 성장을 거의 못하므로, 이 경우 소위 비정상입자성장 을 하게 된다. 여기서 생각해야할 것은 성장구동력은 시간에 따른 함수가 되고 소결 시간이 증가할수록 평 균 입자크기가 증가하면서 전체적인 성장구동력은 감 소할 수 있다. 식 (2)에서 임계입자크기, 평균 입자크 기는 증가하고 결국 성장구동력은 시간이 지날수록 감 소한다. 그렇게 되면 앞에서 설명한 최대성장구동력 과 임계성장구동력과의 관계도 소결 중 시간이 지남 에 따라 계속 변할 수 있다. 그러나 확산 지배의 경우 변하지 않으므로 입자크기 분포의 양상이 변하지 않고 (stationary), 계면 반응이 지배적인 경우, 두 관계가 계 속 변할 수 있기 때문에 입자크기 분포의 양상이 변하게 된다 (nonstationary). ${ }^{16)}$ 그러므로, 지금까지 입자성장 을 정상(正常)입자성장을 normal grain growth로 비정 상(非正常)입자성장을 abnormal grain growth로 분류 하던 것을 각각 정상(定常)입자성장 (stationary grain growth)과 비정상(非定常)입자성장 (nonstationary grain growth)으로 명명하는 것이 더 합당하다고 판단 된다. ${ }^{16)}$ 이는 정상입자성장과 비정상입자성장을 정확히 구분하기 위해서는 소결 시간에 따른 양상을 살펴봐야 함을 강조한다.

임계성장구동력과 관련 되어있는 step free energy는 


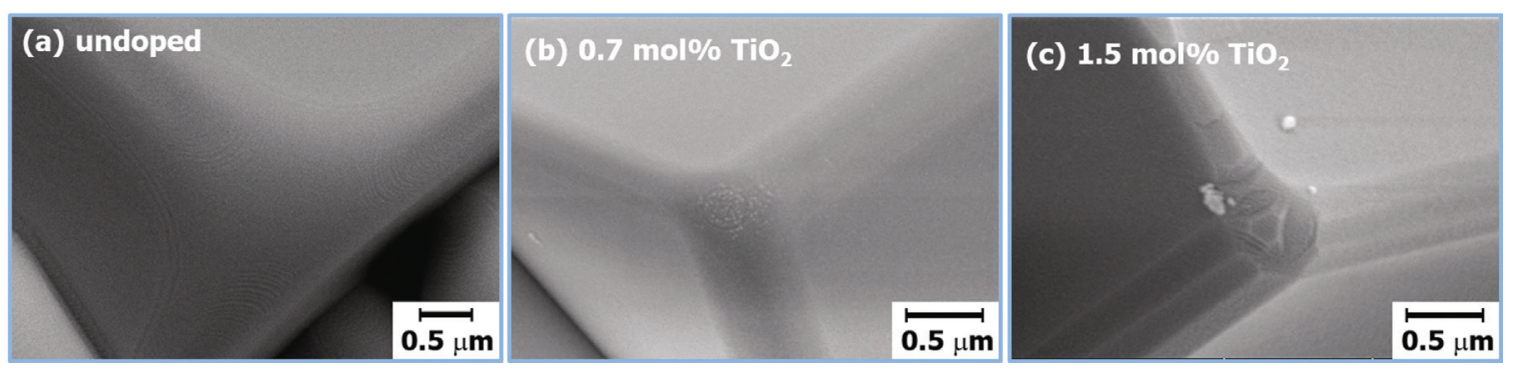

Fig. 3. The three dimensional grain shapes of $0.95 \mathrm{Na}_{0.5} \mathrm{Bi}_{0.5} \mathrm{TiO}_{3}-0.05 \mathrm{BaTiO}_{3}$ annealed at $1200^{\circ} \mathrm{C}$ for $10 \mathrm{~h}$ (a) without $\mathrm{TiO}_{2}$, (b) 0.7 mol\% $\mathrm{TiO}_{2}$, and (c) 1.5 mol\% $\mathrm{TiO}_{2}$. Reproduced from Moon et al. J. Eur. Ceram. Soc., 2011;31:1915-20, with permission from Elsevier [41].

앞에서 설명한 계면 구조와 밀접한 관계가 있다. 계면에 원자 흡착이 용이한 kink 농도가 많아질수록 계면의 구 조는 원자적으로 불규칙한 (disordered) 구조가 되고 불 규칙한 구조가 많아질수록 계면은 둥근 형태가 되고 등 방성이 증가하는 반면, 원자 수준에서 규칙적 (ordered) 인 경우 계면은 편평한 형태가 증가하고 이방성이 증가 하게 된다. ${ }^{1,16,41)}$ 이를 바탕으로, 계면의 구조가 원자적 으로 불규칙한 경우, 즉 입자의 모양이 둥글고 등방적 인 경우는 한 층을 쌓기 쉽게 때문에 step free energy 가 작고 임계성장구동력고 작아진다. 반면 계면의 구조 가 원자적으로 규칙적이고, 입자의 모양이 편평하고 이 방성이 증가하는 경우는 임계성장 구동력이 증가하게 되는 것이다. 그림 3 에서 첨가제의 양에 따른 입자모양 의 변화 예를 볼 수 있다. 이는 무연압전재료 중 하나인 $\mathrm{Na}_{0.5} \mathrm{Bi}_{0.5} \mathrm{TiO}_{3}-\mathrm{BaTiO}_{3}$ 계를 합성하고 $\mathrm{TiO}_{2}$ 를 첨가할 수록 모서리와 꼭지점 부분의 둥근 면이 점차 줄어들고 편평한 면으로 변화함을 보인다. ${ }^{41)} \mathrm{TiO}_{2}$ 를 첨가할수록 step free energy가 증가하고 ${ }^{41)}$ 이로 인해 입자성장 거 동이 달라질 수 있다.

최대성장구동력과 임계성장구동력을 조절함으로써 다 결정체의 입자성장 거동을 제어하고 미세구조를 디자 인하는 전략으로 응용될 수 있다. 최대성장구동력은 식 (2)에서 볼 수 있듯 입자크기와 관련된 것으로 초기입자 의 평균입자크기 및 분포를 조절하여 제어할 수 있다. 임계성장구동력은 소결 온도를 조절하거나, step free energy를 조절해야한다. step free energy는 열역학적 인 변수로 소결 분위기, 소결 온도, 첨가제 등으로 조절
가능하다. ${ }^{6,40)}$ 이 때 평형입자모양의 변화도 함께 관찰 하면, 앞에서 설명한 것과 같이 임계성장구동력이 증가 하는지 감소하는지 판단할 수 있다. 이러한 입자성장 제 어의 전략으로 유전 세라믹스와 자성 세라믹스에 응용 한 실례에 대해 다음 절에서 간단히 알아보고자 한다.

\section{3. 유전 세라믹스에서의 입자성장 제어 응용}

유전 및 강유전, 압전재료로 특성을 다양하게 제어하 여 널리 사용되고 있는 $\mathrm{ABO}_{3}$ 페롭스카이트 산화물에 서도 열역학적 변수를 조절하여 응용별 요구되는 특성 에 맞게 미세구조를 설계할 필요가 있다. 예로, 전자기 기의 모바일 기기 사용 증대 및 기술 발전으로 초소형, 초경량화 되고 있으므로, 내부의 전자부품들도 그 크 기가 급격히 감소하고 있다. 전자부품 중 대표적인 유 전체 재료의 응용 부품인 적층세라믹커패시터 (MLCC, Multilayer Ceramic Capacitor)는 유전체 한 층의 두 께가 수 $\mu \mathrm{m}$ 에서 수백 $\mathrm{nm}$ 의 두께로 감소하고 있다. ${ }^{42)}$ 이로인해 소결 후 유전체 한 층의 크기보다 성장하지 않 도록 입자성장 제어가 반드시 필요하고, 초기 입자크기 또한 나노 수준의 $\mathrm{BaTiO}_{3}$ 를 합성 ${ }^{43)}$ 하려는 노력이 이루 어지고 있다. MLCC용 캐패시터의 유전체는 치밀한 구 조를 가져야 하며, 입자성장이 억제되어야하므로, 입자 성장이 억제되는 조건에서 치밀한 구조를 확보하기 위 한 미세구조 제어 전략이 필요하다.

압전세라믹스의 경우, 1880년 프랑스 Pierre와 Jacques Curie 형제에 의해 압전 효과가 실험적으 로 발견된 이후 ${ }^{44}{ }^{45}$ 그 동안 우수한 압전특성을 갖는 


\section{특 집 표 문경석}

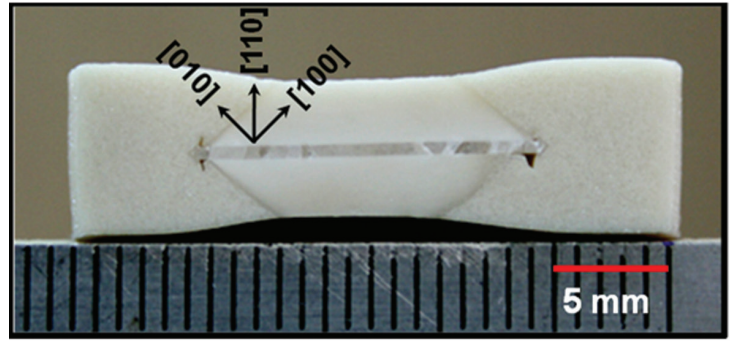

(a)

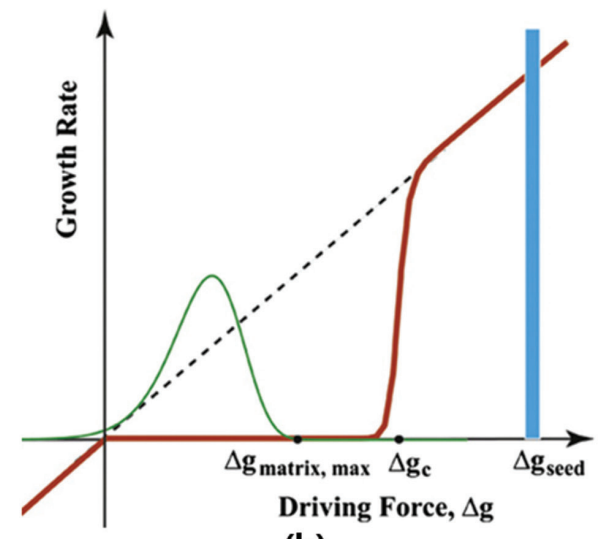

(b)

Fig. 4. (a) A photograph showing a $0.95 \mathrm{Na}_{0.5} \mathrm{Bi}_{0.5} \mathrm{TiO}_{3}-0.05 \mathrm{BaTiO}_{3}(\mathrm{NBT}-5 \mathrm{BT})$ single crystal grown from an $\mathrm{SrTiO}_{3}$ seed crystal into NBT-5BT matrix grains in a sample sintered at $1200^{\circ} \mathrm{C}$ for $10 \mathrm{~h}$. (b) Schematic showing the growth rate of a grain as a function of the driving force for growth. A Schematic grain size distribution as a function of driving force is also plotted. $\Delta \mathrm{g}_{\text {max,matrix }}$ is the maximum driving force for growth in the matrix and $\Delta \mathrm{g}_{\text {seed }}$ is the driving force for growth of the seed crystal. Reproduced from Moon et al. J. Cryst. Growth, 2011;317:28-31, with permission from Elsevier [54].

$\mathrm{Pb}(\mathrm{Zr}, \mathrm{Ti}) \mathrm{O}_{3}(\mathrm{PZT})$ 계의 다결정체를 중심으로 개발이 이루어졌다. 압전 세라믹스의 경우도, MLCC와 같이 적 층 구조로 사용될 수 있으며 이 때도 기계적 특성과 압 전특성 향상을 위해 치밀화 및 입자성장 제어가 필요하 고, 단결정으로 제조하는 경우 그 특성이 매우 향상될 수 있다. ${ }^{46-49)}$ 고상단결정성장법 (Solid-state Single Crystal Growth, SSCG $)^{2,31,50-52)}$ 은 압전 단결정을 제 조하는 기술로, 미세구조의 설계와 제어를 그 요체로 한다. 고상단결정성장법은 기존의 모든 재료를 용융하 여 냉각하면서 단결정 성장을 하는 Flux, Czochralski, modified Bridgeman method 등의 고온 용융법과는 달리 입자를 용융 시키지 않고 단지 소결 공정을 통해 고상입자가 다결정체 내에서 혹은 액상이 존재하는 다 결정체 내에서 비정상입자성장 현상을 이용하여 일부의 고상 입자를 거대하게 성장시키는 방법이다. ${ }^{2,53)}$ 고상단 결정성장법을 응용하기 위해서는 비정상입자성장 현상 을 반드시 이해해야 한다. ${ }^{53)}$

그 림 4 는 무연 압전 소재 중 하나 인 $0.95 \mathrm{Na}_{0.5} \mathrm{Bi}_{0.5} \mathrm{TiO}_{3}-0.05 \mathrm{BaTiO}_{3}(\mathrm{NBT}-5 \mathrm{BT})$ 계에서 $\mathrm{SrTiO}_{3}$ 를 seed로 하여 고상단결정성장한 예를 보여준 다. ${ }^{54)}$ 그림 4(a)에서 보면 $\{100\}$ 면 $\mathrm{SrTiO}_{3}$ 기판을 seed
로 사용하였고, 그 위로 NBT-5BT 입자 하나가 다른 다결정체 대비 매우 큰 입자로 성장한 것을 볼 수 있다. NBT-5BT의 평형입자모양은 $\{100\}$ 면이 안정하므로, $\{110\}$ 면 seed를 사용하더라도, 최종적으로 $\{100\}$ 면이 나 타나는 것을 확인할 수 있었다. 초기에 분말성형체에 $\mathrm{SrTiO}_{3}$ 를 seed로 넣고 성형하여 소결하게 되는데, 하소 후 합성된 초기의 분말들은 평균입자크기가 $0.3 \mu \mathrm{m}$ 이며, 최대 $0.6 \mu \mathrm{m}$ 이상 되는 입자를 갖지 않은 상태이다. ${ }^{41}$ 그림 4(b)에서 seed를 제외한 입자들의 성장구동력은 모 두 최대성장구동력보다 작은 상태가 되고, 이 때 $\mathrm{SrTiO}_{3}$ seed의 경우 그 크기가 NBT-5BT 분말보다 상당히 큰 상태가 되므로, 그 seed 크기에 대응하는 최대성장구동 력으로 NBT-5BT의 고상입자가 seed로부터 성장하게 된다. Seed의 크기는 분말에 비해 매우 크기 때문에 그 성장구동력 또한 임계성장구동력봐 훨씬 큰 성장구동력 을 갖게 된다 (그림 4(b)). 고상단결정성장법을 적용시 키기 위해서는 2 차원 핵생성 및 입자성장에 의한 비정상 입자성장 거동에 의해 입자성장이 일어나야 하는데, 첨 가제가 없는 $\mathrm{NBT}-5 \mathrm{BT}$ 의 경우, $1200^{\circ} \mathrm{C}$ 에서 소결할 경 우 대부분의 입자가 함께 성장하기 때문에 ${ }^{16)}$ 비정상의 입자들이 서로 충돌하여 단결정 성장에 한계가 있다. 이 


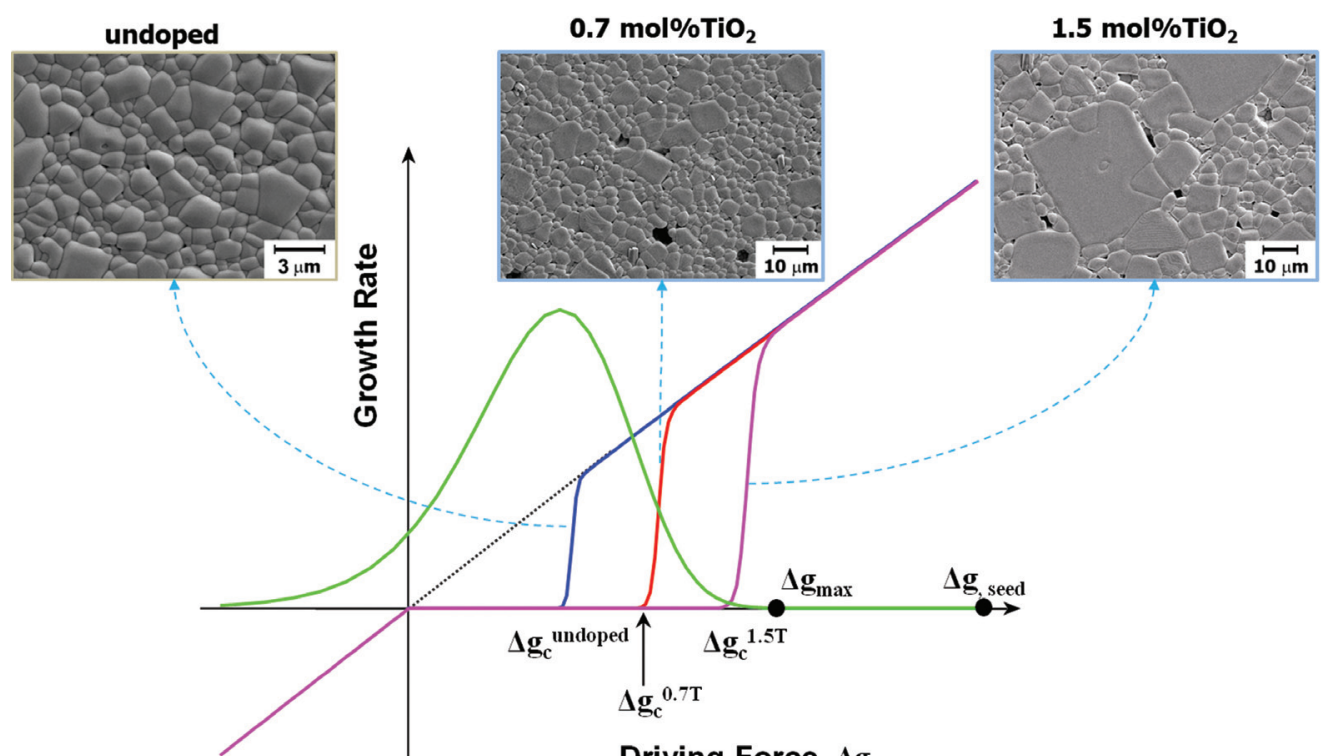

Driving Force, $\Delta \mathbf{g}$

Fig. 5. Schematic showing the growth rate of a crystal as a function of the driving force. For mixed control, three curves are plotted for undoped (OT), $0.7 \mathrm{~mol} \% \mathrm{TiO}_{2}$-doped, and $1.5 \mathrm{~mol} \% \mathrm{TiO}_{2}$-doped $95 \mathrm{Na}_{0.5} \mathrm{Bi}_{0.5} \mathrm{TiO}_{3}-$ $5 \mathrm{BaTiO}_{3}$ samples with their SEM micrographs. Reproduced from Moon et al. J. Eur. Ceram. Soc., 2011;31:1915-20, with permission from Elsevier [41].

때 입자의 모양은 $\{100\}$ 면이 안정하고, 모서리가 둥근 입방정 형태로 ${ }^{16)}$ 비정상입자성장 거동을 유도하기 위해 서는 둥근 모서리 부분의 분율을 감소시켜 더 각진형태 가 된다면 step free energy가 증가하고 임계성장구동 력도 증가하여 일부 입자만 성장시킬 수 있다. 한 예로, 그림 3 에서와 같이 $\mathrm{TiO}_{2}$ 를 첨가하여 더 각진 형태의 평 형입자모양을 한 NBT-5BT 계의 입자를 만들 수 있고, 이 경우 그림 5 와 같이 $\mathrm{TiO}_{2}$ 가 첨가될 수록 비정상입자 성장이 확연해지는 것을 확인할 수 있었다. ${ }^{41)}$ 이는 그 림 5 에서 나타낸 입자성장과 입자성장 모식도에서 초기 의 최대성장구동력은 고정된 상태에서 $\mathrm{TiO}_{2}$ 첨가의 양 이 증가할수록 임계성장구동력이 증가하는 것으로 판단 할 수 있고, 이를 입자모양의 변화와 함께 확인할 수 있 었다.

\section{4. 자성 세라믹스에서의 입자성장 제어 응용}

자성 세라믹스는 모터나 센서, 전자파차폐, 안테나 등 에 활용되는 소재로, 영구자석과 연장성에 따라 그 응 용 분야가 달라진다. 대표적인 세라믹 영구자석으로 대
표적인 $\mathrm{M}$-type $(\mathrm{Ba}, \mathrm{Sr})$ hexaferrite의 소형 경량화 및 고성능을 위해서는 $(\mathrm{BH})_{\max }$ 값을 증대시켜야 한다. ${ }^{55)}$ $(\mathrm{BH})_{\max }$ 값은 포화 자화 $\left(M_{c}\right)$ 를 $\mathrm{La}, \mathrm{Ca}, \mathrm{Co}$ 등을 치환 첨가하여 증대시키거나 ${ }^{56-60)}$ 보자력을 증대시키는 전략 으로 소재 개발이 이루어진다. ${ }^{61-63)}$ 영구 자석 세라믹스 의 경우 큰 보자력 $\left(H_{c}\right)$ 은 영구자석에서 필히 요구되는 특성이고, 조성 설계에 의해 증가되는 것보다, 입자크기 에 의존하는 인자로 ${ }^{61-63)}$ 미세구조를 제어하면 그 특성 을 향상시킬 수 있다. 보자력은 소결 후 입자크기가 감 소함에 따라 증가하고, 점차 증가하다가 domain 크기와 비슷해졌을 때 최고값에 도달 한 후 다시 줄어들게 된 다. ${ }^{34,36,55)}$ 입자크기를 감소시키는 가장 확실한 방법은 소결 온도를 감소시켜 입자성장을 억제하는 방법이 있 으나, 분말성형 후 입자성장이 거의 일어나지 않을 경우 치밀화가 되지 않는다. 입자크기는 감소시킬 수 있더라 도, 모터 등 영구 자석으로 응용되기 위해서는 그 강도 도 매우 중요한데 치밀한 구조를 확보하지 못한다면 응 용이 불가하다. 그러므로 치밀화되면서 입자성장이 억 제되도록 해야한다. $\mathrm{M}$-type $(\mathrm{Ba}, \mathrm{Sr})$ hexaferrite은 


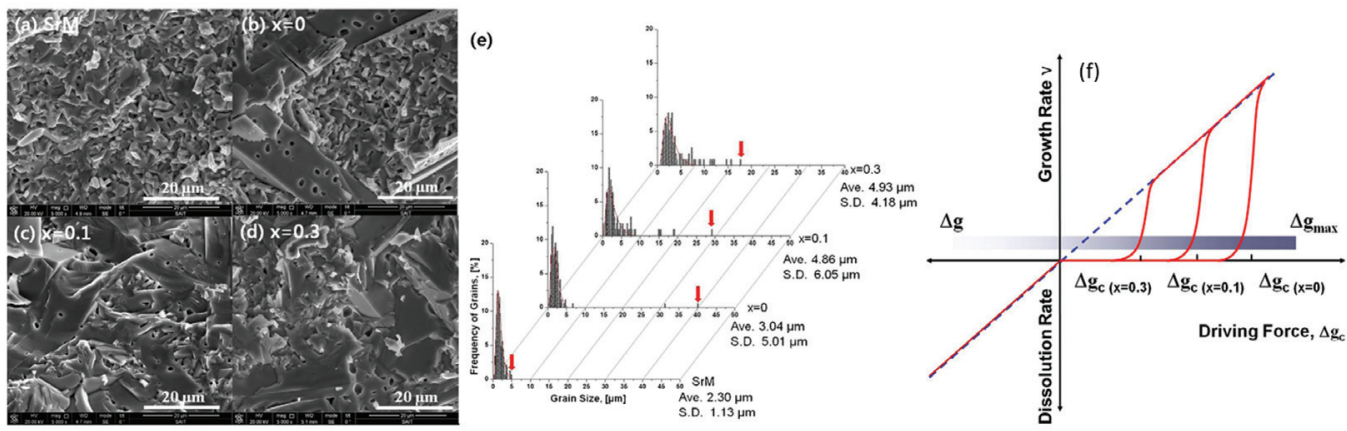

Fig. 6. Micrographs of (a) $\mathrm{SrFe}_{12} \mathrm{O}_{19}(\mathrm{SrM})$ and $\mathrm{Sr}_{1-x} \mathrm{Ca}_{x} \mathrm{Fe}_{11.7} \mathrm{Mn}_{0.1} \mathrm{Zn}_{0.1} \mathrm{O}_{19}$ with (b) $x=0$, (c) $x=0.1,(\mathrm{~d}) x=0.3$ and (e) their grain size distributions. The largest grain in each sample is indicated by an arrow. (f)Schematic representation showing the growth rate of a crystal as a function of the driving force for grain growth of hexaferrites $\left(\mathrm{Sr}_{1-x} \mathrm{Ca}_{x} \mathrm{Fe}_{11.7} \mathrm{Mn}_{0,1} \mathrm{Zn}_{0.1} \mathrm{O}_{19}\right)$. Reproduced from Moon et al. J. Eur. Ceram. Soc., 2016;36:3383-89, with permission from Elsevier [34].

육방정 구조로, 평형입자모양의 경우 이방성을 갖고 입 자성장은 2 차원 핵생성에 의해 성장하는 것으로 판단되 나, 관련된 연구 결과는 부족하다. 한 예로, 그림 6 에서 보는 바와 같이, 기본 $\mathrm{SrFe}_{12} \mathrm{O}_{19}(\mathrm{SrM})$ 계에서 각 치환 자리에 다른 원소를 치환한 $\mathrm{Sr}_{1-\mathrm{x}} \mathrm{Ca}_{\mathrm{x}} \mathrm{Fe}_{11,7} \mathrm{Mn}_{0.1} \mathrm{Zn}_{0.1} \mathrm{O}_{19}$ 계의 소결 후 미세구조와 입자크기 분포도를 보면, ${ }^{34)}$ 상 대적으로 크게 성장한 입자의 경우 한쪽 방향으로 길게 성장한 모습을 하고 있다. 이방성을 갖고 일부만 성장 하는 비정상입자성장 거동이 보이므로, 2 차원 핵생성에 의한 입자성장으로 설명이 가능할 것이다. $\mathrm{Ca}$ 첨가량이 증가할수록 초기에 일부의 입자만 거대하게 성장한 상 태에서 입자크기분포도 (그림. $6(\mathrm{e})$ )에서 볼 수 있듯이 최대 입자크기가 오히려 감소하고, 입자크기분포가 균 일해지는 것을 확인할 수 있다. 이는 그림 $6(\mathrm{f})$ 에서와 같 이 $\mathrm{Ca}$ 양이 증가하면서 임계성장구동력이 감소하여 성 장할 수 있는 입자의 수가 증가하게 되고, 성장하는 입 자의 수는 증가하되, 그 크기는 감소하는 것으로 설명할 수 있다.

최근 이동통신 및 정보 기술의 발전으로, 모바일 기 기 생활화, 각종 웨어러블 디바이스, 자율주행자동차 시 대로 스마트 모빌리티 (smart mobility) 분야로 산업 의 패러다임이 급속히 변화되고 있기 때문에, 전자기기 에 사용되는 안테나나 전자부품 간의 간섭을 방지하는 전자파차폐 기술에 고주파화가 요구된다. ${ }^{64-71)}$ 연자성의 Z-type hexaferrite 인 $\mathrm{Ba}_{3} \mathrm{Co}_{2} \mathrm{Fe}_{24} \mathrm{O}_{41}$ 의 경우 자석-유
전체 (magneto-dielectric, $\mathrm{MD}$ )의 대표적인 조성으로 $\operatorname{VHF}(30-300 \mathrm{MHz})$ 와 $\mathrm{UHF}(0.3-3.0 \mathrm{GHz})$ 에 적용 가능한 소재이다. ${ }^{65,72,73)}$ 자기적 특성인 투자율을 향상 시킬 필요가 있고, 이를 위해서는 입자 형상의 이방성을 증가시켜야 한다. ${ }^{65)}$ 그림 7 은 $\mathrm{Ba}_{3} \mathrm{Co}_{2} \mathrm{Fe}_{24} \mathrm{O}_{41}$ 계에서 $\mathrm{Ba}$ 자리에 $\mathrm{Sr}$ 을 일부 치환하여, 이방적 형태의 입자를 합성 한 결과를 보여준다. ${ }^{71)}$ Z-type hexaferrite은 M-type hexaferrite 대비 높은 온도에서 합성이 되는 소재로 ${ }^{68)}$ Z-type의 hexaferrite 상 형성을 위해서는 고온이 필 요하나 열처리 온도가 증가할수록 계면이 원자적으로 불규칙해지고 이방성이 감소하며, 성장속도가 증가하여 두께도 증가하므로 이방성이 더욱 감소할 것으로 예상 된다. 그림 7에서, 소결 온도가 증가할수록 합성된 입자 의 두께가 증가하는 것을 볼 수 있으며, 이는 그림 7(b) 에서 소결 온도 증가 시 임계성장구동력이 감소하고 입 자 형상도 등방적으로 변화하는 것으로 설명할 수 있다.

\section{3. 결론}

세라믹 재료의 소결 중 일어나는 입자성장 현상에 대 해 그 이론과 입자성장 제어의 전략으로 유전 세라믹스 와 자성 세라믹스에 응용한 실례에 대해 알아보았다. 세 라믹 재료의 입자성장 현상은 계면의 원자 수준에서의 구조 차이에 의해 달리 나타난다. 또한 계면의 구조 차 이에 의해 평형입자모양도 다르게 나타난다. 입자 성장 


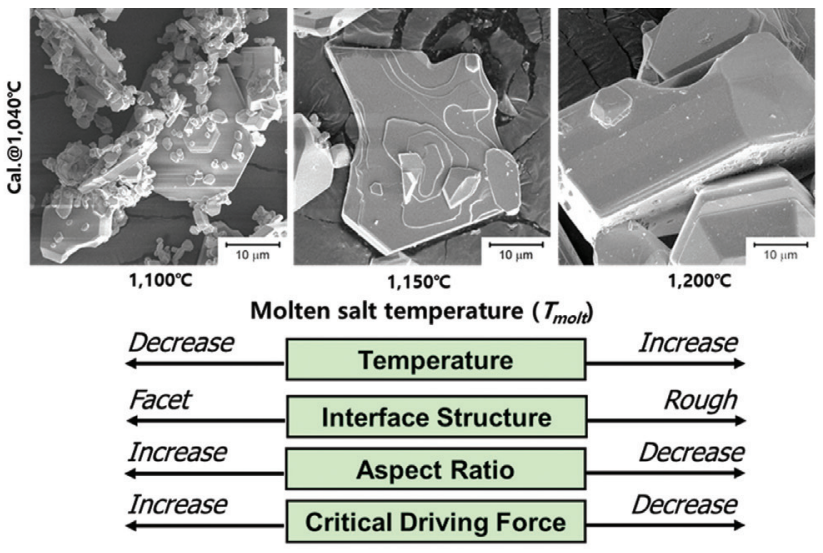

(a)

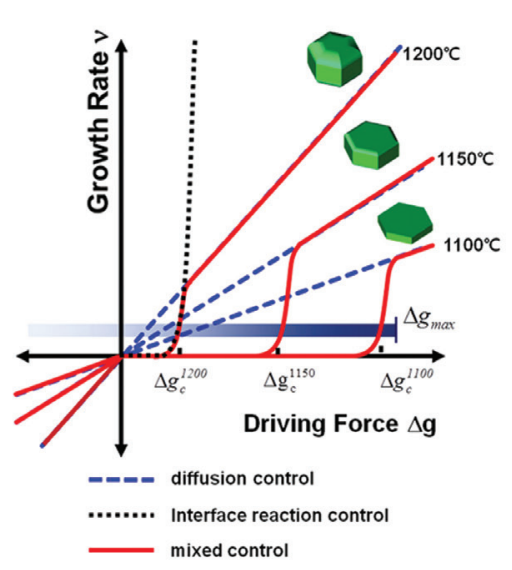

(b)

Fig. 7. (a) Scanning electron micrographs of $\mathrm{Ba}_{1.5} \mathrm{Sr}_{1.5} \mathrm{CO}_{2} \mathrm{Fe}_{24} \mathrm{O}_{41}$ powder samples with various temperatures. (b) schematic of the growth rate as a function of the driving force for diffusion, interface reaction, and mixed control (red solid line). The color gradient denotes a range of driving forces for growth and shrinkage. Reproduced from Moon et al. J. Appl. Phys. Soc., 2016;120:194102, with permission from AIP Publishing [71].

구동력은 임계입자의 크기 혹은 평균입자의 크기와 입 자 간의 곡률 차이로 인한 모세관력으로써, 입자크기 가 분포를 가지는 것과 마찬가지로 성장구동력도 분포 를 가지게 된다. 이 때 가장 큰 입자가 최대성장구동력 을 갖게 되고, 임계성장구동력과의 관계에 따라 성장 할 수 있는 입자의 분율, 즉, 입자성장 거동이 달라지 는 것을 정리하였다. 소결 시간이 증가할수록 성장구동 력은 감소하게 되며 이 때 최대성장구동력과 임계성장 구동력과의 관계가 변하게 되므로 입자성장 거동은 소 결 시간이 지남에 따라 변할 수 있다. 이것이 비정상입 자성장이다. 기존의 정상(正常)입자성장 (normal grain growth)과 비정상(非正常)입자성장 (abnormal grain growth)을 각각 정상(定常)입자성장 (stationary grain growth)과 비정상(非定常)입자성장 (nonstationary grain growth)으로 표현하는 것이 더 현실적이라고 생 각된다. 2 차원 핵생성 및 성장에 의한 이론을 유전 세라 믹과 자성 세라믹스에 적용하여 미세구조가 어떻게 달 라질 수 있는지 살펴보았고, 이를 이용하면 응용 분야에 따라 요구되는 특성에 맞는 미세구조를 디자인할 수 있 을 것이다.

\section{REFERENCES}

1. S.-J. L. Kang, "Sintering: Densification, Grain Growth and Microstructure." Elsevier Butterworth-Heinemann: Oxford, UK, (2005).

2. H.-T. Oh, H.-J. Joo, M.-C. Kim, H.-Y. Lee, "Effect of Mn on Dielectric and Piezoelectric Properties of 71PMN-29PT [71Pb( $\left.\left.\mathrm{Mg}_{1 / 3} \mathrm{Nb}_{2 / 3}\right) \mathrm{O}_{3}-29 \mathrm{PbTiO}_{3}\right]$ Single Crystals and Polycrystalline Ceramics." J. Korean Ceram. Soc., 55[2] 166-173 (2018).

3. S.-J. L. Kang and S. M. Han, "Grain-Growth in $\mathrm{Si}_{3} \mathrm{~N}_{4}$ Based Materials," MRS Bulletin, 20[2] 33-37 (1995).

4. Y. J. Park, N. M. Hwang, and D. Y. Yoon, “Abnormal growth of faceted (WC) grains in a (Co) liqiud matrix," Metall. Mater. Trans. a-Phys. Metall. Mater. Sci., 27[9] 2809-19 (1996).

5. D. Y. Yoon, C. W. Park, and J. B. Koo, “The step growth hypothesis for abnormal grain growth," pp. 3-21: London, UK, (2001).

6. S.-J. L. Kang, M. G. Lee, and S. M. An, "Microstructural evolution during sintering with control of the interface structure," J. Am. Ceram. Soc., 92[7] 1464-71 (2009).

7. C. H. P. Lupis, "Chemical Thermodynamics of Materials.” Prentice Hall Inc.: New Jersey, (1993).

8. I. M. Lifshitz and V. V. Slyozov, "The kinetics of precipitation from supersaturated solid solutions," $J$. Phys. Chem. Solids, 19 35-50 (1961). 
9. C. Wagner, "Theory of precipitate change by redissolution," Z. Elechem., 65 581-91 (1961).

10. A. J. Ardell, "The effect of volume fraction on particle coarsening: theoretical considerations," Acta Metall., 20[1] 61-71 (1972).

11. Y.-I. Jung, S. Y. Choi, and S.-J. L. Kang, "Effect of oxygen partial pressure on grain boundary structure and grain growth behavior in $\mathrm{BaTiO}_{3}$," Acta Mater., 54[10] 2849-55 (2006).

12. M. S. Kim, J. G. Fisher, S.-J. L. Kang, and H. Y. Lee, "Grain growth control and solid-state crystal growth by $\mathrm{Li}_{2} \mathrm{O} / \mathrm{PbO}$ addition and dislocation introduction in the PMN-35PT system," J. Am. Ceram. Soc., 89[4] 1237-43 (2006).

13. J. G. Fisher, S. Y. Choi, and S.-J. L. Kang, "Abnormal grain growth in barium titanate doped with alumina," J. Am. Ceram. Soc., 89[7] 2206-12 (2006).

14. S.-J. L. Kang, Y.-I. Jung, and K.-S. Moon, "Principles of Microstructural Design in Two-Phase Systems," Mater. Sci. Forum, 558-559 827-34 (2007).

15. S. Y. Choi, S.-J. L. Kang, and S. Y. Chung, “Abnormal grain growth and intergranular amorphous film formation in $\mathrm{BaTiO}_{3}$," J. Am. Ceram. Soc., 90[2] 64548 (2007).

16. K.-S. Moon and S.-J. L. Kang, "Coarsening Behavior of Round-Edged Cubic Grains in the $\mathrm{Na}_{1 / 2} \mathrm{Bi}_{1 / 2} \mathrm{TiO}_{3^{-}}$ $\mathrm{BaTiO}_{3}$ System," J. Am. Ceram. Soc., 91[10] 3191-96 (2008).

17. D.-Y. Yang and S.-J. L. Kang, "Suppression of abnormal grain growth in WC-Co via pre-sintering treatment," Inter. J. Refractory Metal. Hard Mater., 27[1] 90-94 (2009).

18. P. W. Atkins and J. d. Paula, "Physical Chemistry." Oxford University Press: Oxford, UK, (2010).

19. R. Warren, "Microstructural Development During Liquid-Phase Sintering of VC-Co Alloys," J. Mater. Sci., 7[12] 1434-42 (1972).

20. T. K. Kang and D. N. Yoon, "Coarsening of Tungsten Grains in Liquid Nickel-Tunsten Matrix," Metall. Mater. Trans. a-Phys. Metall. Mater. Sci., 9A 433-38 (1978).

21. C. H. Kang and D. N. Yoon, "Coarsening of Cobalt Grains Dispersed in Liquid Copper Matrix," Metall. Mater. Trans. a-Phys. Metall. Mater. Sci., 13A 65-69 (1981).

22. S. S. Kang and D. N. Yoon, "Kinetics of Grain
Coarsening during sintering of $\mathrm{Co}-\mathrm{Cu}$ and $\mathrm{Fe}-\mathrm{Cu}$ Alloys with Low Liquid Contents," Metall. Mater. Trans. a-Phys. Metall. Mater. Sci., 13A 1405-11 (1982).

23. M. M. Seabaugh, I. H. Kerscht, and G. L. Messing, "Texture development by templated grain growth in liquid-phase-sintered alpha-alumina," J. Am. Ceram. Soc., 80[5] 1181-88 (1997).

24. S. K. Kwon, S. H. Hong, D. Y. Kim, and N. M. Hwang, "Coarsening behavior of tricalcium silicate $\left(\mathrm{C}_{3} \mathrm{~S}\right)$ and dicalcium silicate $\left(\mathrm{C}_{2} \mathrm{~S}\right)$ grains dispersed in a clinker melt," J. Am. Ceram. Soc., 83[5] 1247-52 (2000).

25. S. Y. Chung and S.-J. L. Kang, "Effect of dislocations on grain growth in strontium titanate," J. Am. Ceram. Soc., 83[11] 2828-32 (2000).

26. C. W. Park and D. Y. Yoon, "Effects of $\mathrm{SiO}_{2}, \mathrm{CaO}_{2}$, and $\mathrm{MgO}$ additions on the grain growth of alumina," J. Am. Ceram. Soc., 83[10] 2605-09 (2000).

27. M. J. Kim and D. Y. Yoon, "Effect of magnesium oxide addition on surface roughening of alumina grains in anorthite liquid," J. Am. Ceram. Soc., 86[4] 630-33 (2003).

28. J. G. Fisher, M. S. Kim, H. Y. Lee, and S.-J. L. Kang, "Effect of $\mathrm{Li}_{2} \mathrm{O}$ and $\mathrm{PbO}$ additions on abnormal grain growth in the $\mathrm{Pb}\left(\mathrm{Mg}_{1 / 3} \mathrm{Nb}_{2 / 3}\right) \mathrm{O}_{3}-35 \mathrm{~mol} \% \mathrm{PbTiO}_{3}$ system," J. Am. Ceram. Soc., 87[5] 937-42 (2004).

29. Y. K. Cho, D. Y. Yoon, and B. K. Kim, "Surface roughening transition and coarsening of $\mathrm{NbC}$ grains in liquid cobalt-rich matrix," J. Am. Ceram. Soc., 87[3] 443-48 (2004).

30. B. K. Yoon, B. A. Lee, and S.-J. L. Kang, "Growth behavior of rounded $(\mathrm{Ti}, \mathrm{W}) \mathrm{C}$ and faceted $\mathrm{WC}$ grains in a Co matrix during liquid phase sintering," Acta Mater, 53[17] 4677-85 (2005).

31. E. P. Gorzkowski, H. M. Chan, and M. P. Harmer, "Effect of $\mathrm{PbO}$ on the kinetics of $\{001\}$ $\mathrm{Pb}\left(\mathrm{Mg}_{1 / 3} \mathrm{Nb}_{2 / 3}\right) \mathrm{O}_{3}-35 \mathrm{~mol} \% \mathrm{PbTiO}_{3}$ single crystals grown into fully dense matrices," J. Am. Ceram. Soc., 89[3] 856-62 (2006).

32. W. Jo, D. Y. Kim, and N. M. Hwang, "Effect of interface structure on the microstructural evolution of ceramics," J. Am. Ceram. Soc., 89[8] 2369-80 (2006).

33. T. Sano and G. S. Rohrer, "Experimental evidence for the development of bimodal grain size distributions by the nucleation-limited coarsening mechanism," $J$. 
Am. Ceram. Soc., 90[1] 211-16 (2007).

34. K.-S. Moon and Y.-M. Kang, "Structural and magnetic properties of Ca-Mn-Zn-substituted M-type Sr-hexaferrites," J. Eur. Ceram. Soc., 36[14] 3383-89 (2016).

35. K.-S. Moon, "Effect of $\mathrm{Na}_{2} \mathrm{CO}_{3}$ Addition on Grain Growth Behavior and Solid-state Single Crystal Growth in the $\mathrm{Na}_{0.5} \mathrm{Bi}_{0.5} \mathrm{TiO}_{3}-\mathrm{BaTiO}_{3}$ System," J. Kor. Powder Metall. Inst., 25[2] 104-08 (2018).

36. K.-S. Moon, P.-Y. Yu, and Y.-M. Kang, "Microstructure and Magnetic Properties of La-Ca-Co Substituted M-Type Sr-Hexaferrites with Controlled Si Diffusion," Appl. Sci., 10[21] 7570 (2020).

37. D. A. Porter and K. E. Easterling, "Phase Transformations in Metals and Alloys," 2nd ed. Stanley Thornes Ltd.: UK, (1992).

38. J. M. Howe, “Interfaces in Materials," 1st ed. John Wiley \& Sons: NY, (1997).

39. Y. I. Jung, D. Y. Yoon, and S.-J. L. Kang, "Coarsening of polyhedral grains in a liquid matrix," J. Mater. Res., 24[9] 2949-59 (2009).

40. Y.-I. Jung, D. Y. Yoon, and S.-J. L. Kang, "Model Calculation of Grain Growth in a Liquid Matrix," Mater. Sci. Forum, 534-536 569-72 (2007).

41. K.-S. Moon , D. Rout, H.-Y. Lee, and S.-J. L. Kang, "Effect of $\mathrm{TiO}_{2}$ addition on grain shape and grain coarsening behaviour in $95 \mathrm{Na}_{1 / 2} \mathrm{Bi}_{1 / 2} \mathrm{O}_{3}-\mathrm{BaTiO}_{3}, " \mathrm{~J}$. Eur. Ceram. Soc., 31 1915-20 (2011).

42. M. Pan and C. A. Randall, "A brief introduction to ceramic capacitors," IEEE Electr. Insul. Mag., 26[3] 44-50 (2010).

43. S. Moon, H.-W. Lee, C.-H. Choi, and D. K. Kim, "Influence of Ammonia on Properties of Nanocrystalline Barium Titanate Particles Prepared by a Hydrothermal Method," J. Am. Ceram. Soc., 95[7] 2248-53 (2012).

44. B. Jaffe, W. R. Cook, and H. Jaffe, "Piezoelectric Ceramics," Vol. 3. Academic Press: London and New York, (1971).

45. E. Cross, "Lead-free at last," Nature, 432[7013] 24-25 (2004).

46. S. E. Park, "Relaxor based ferroelectric single crystals for electro-mechanical actuators," Mater. Res. Innov., 1[1] 20-25 (1997).

47. S. E. Park and T. R. Shrout, "Ultrahigh strain and piezoelectric behavior in relaxor based ferroelectric single crystals," J. Appl. Phys., 82[4] 1804-11 (1997).

48. S. E. Park and W. Hackenberger, "High performance single crystal piezoelectrics: Applications and issues," Curr. Opin. Solid State Mater. Sci., 6[1] 11-18 (2002).

49. L. Luo, H. Wang, Y. Tang, X. Zhao, Z. Feng, D. Lin, and H. Luo, "Ultrahigh transverse strain and piezoelectric behavior in $(1-x) \mathrm{Pb}\left(\mathrm{Mg}_{1 / 3} \mathrm{Nb}_{2 / 3}\right)$ $\mathrm{O}_{3}-x \mathrm{PbTiO}_{3}$ crystals," J. Appl. Phys., 99[2] 1-4 (2006).

50. P. T. King, E. P. Gorzkowski, A. M. Scotch, D. J. Rockosi, H. M. Chan, and M. P. Harmer, "Kinetics of $\{001\} \mathrm{Pb}\left(\mathrm{Mg}_{1 / 3} \mathrm{Nb}_{2 / 3}\right) \mathrm{O}_{3}-35 \mathrm{~mol} \% \mathrm{PbTiO}_{3}$ single crystals grown by seeded polycrystal conversion," $J$. Am. Ceram. Soc., 86[12] 2182-87 (2003).

51. A. Khan, E. P. Gorzkowski, A. M. Scotch, E. R. Leite, T. Li, H. M. Chan, and M. P. Harmer, "Influence of excess $\mathrm{PbO}$ additions on $\{111\}$ single-crystal growth of $\mathrm{Pb}\left(\mathrm{Mg}_{1 / 3} \mathrm{Nb}_{2 / 3}\right) \mathrm{O}_{3}-35 \mathrm{~mol} \% \mathrm{PbTiO}_{3}$ by seeded polycrystal conversion," J. Am. Ceram. Soc., 86[12] 2176-81 (2003).

52. D. J. Rockosi, E. P. Gorzkowski, P. T. King, A. M. Scotch, H. M. Chan, and M. P. Harmer, "Seeded growth from twinned and untwinned abnormal grains of $\mathrm{Pb}\left(\mathrm{Mg}_{1 / 3} \mathrm{Nb}_{2 / 3}\right) \mathrm{O}_{3}-35$ mol\% $\mathrm{PbTiO}_{3}$ in a matrix containing $\mathrm{PbO}$ additions," J. Am. Ceram. Soc., 87[7] 1339-42 (2004).

53. K.-S. Moon, “ Microstructure control and solid-state single crystal growth in the $\mathrm{Na}_{1 / 2} \mathrm{Bi}_{1 / 2} \mathrm{TiO}_{3}-\mathrm{BaTiO}_{3}$ System," in Department of Materials Science and Engineering, Ph. D. Korea Advanced Institute of Science and Technology (KAIST), Daejeon, Republic of Korea, 2010.

54. K.-S. Moon, D. Rout, H.-Y. Lee, and S.-J. L. Kang, "Solid state growth of $\mathrm{Na}_{1 / 2} \mathrm{Bi}_{1 / 2} \mathrm{TiO}_{3}-\mathrm{BaTiO}_{3}$ single crystals and their enhanced piezoelectric properties," J. Cryst. Growth, 317[1] 28-31 (2011).

55. R. C. Pullar, "Hexagonal ferrites: A review of the synthesis, properties and applications of hexaferrite ceramics," Prog. Mater. Sci., 57[7] 1191-334 (2012).

56. J. Bai, X. Liu, T. Xie, F. Wei, and Z. Yang, "The effects of La-Zn substitution on the magnetic properties of Sr-magnetoplumbite ferrite nanoparticles," Mater. Sci. Eng.: B, 68[3] 182-85 (2000).

57. Y. Ogata, T. Takami, and Y. Kubota, "Development of La-Co Substituted Ferrite Magnets," J. Jpn. Soc. Pow. Pow. Metall., 50[8] 636-41 (2003). 
58. Y.-M. Kang, Y.-H. Kwon, M.-H. Kim, and D.-Y. Lee, "Enhancement of magnetic properties in $\mathrm{Mn}$ Zn substituted M-type Sr-hexaferrites," J. Mag. Mag. Mater., 382 10-14 (2015).

59. Y.-M. Kang and K.-S. Moon, "Magnetic properties of Ce-Mn substituted M-type Sr-hexaferrites," Ceram. Int., 41[10, Part A] 12828-34 (2015).

60. Y.-M. Kang, "High saturation magnetization in LaCe-Zn-doped M-type Sr-hexaferrites," Ceram. Int., 41[3, Part B] 4354-59 (2015).

61. K. J. Sixtus, K. J. Kronenberg, and R. K. Tenzer, "Investigations on Barium Ferrite Magnets," J. Appl. Phys., 27[9] 1051-57 (1956).

62. H. Nishio, Y. Minachi, and H. Yamamoto, "Effect of Factors on Coercivity in Sr-La-Co Sintered Ferrite Magnets," IEEE Trans. Magn., 45[12] 5281-88 (2009).

63. Y.-M. Kang, J. Lee, Y. J. Kang, J.-B. Park, S. I. Kim, S. M. Lee, and K. Ahn, "Understanding on coercivity behavior of M-type strontium hexaferrite through thin-film experiment and micromagnetic modeling," Appl. Phys. Lett., 103[12] 122407 (2013).

64. Z. W. Li, L. Chen, and C. K. Ong, "High-frequency magnetic properties of $\mathrm{W}$-type barium-ferrite $\mathrm{BaZn}_{2-}$ ${ }_{x} \mathrm{Co}_{\mathrm{x}} \mathrm{Fe}_{16} \mathrm{O}_{27}$ composites," J. Appl. Phys., 945918 (2003).

65. G. Q. Lin, Y. P. Wu, and Z. W. Li, "Improvement of the electromagnetic properties in composites with flaky-like $\mathrm{Co}_{2} \mathrm{Z}$ powders by molten-salt synthesis," IEEE Trans. Magn., 423326 (2006).

66. L. B. King, Z. W. Li, G. Q. Lin, and Y. B. Gan,
"Magneto-dielectric properties of $\mathrm{Mg}-\mathrm{Cu}-\mathrm{Co}$ ferrite ceramics: II. Electrical, dielectric, and magnetic properties," J. Am. Ceram. Soc., 902104 (2007).

67. Z. W. Li, Z. H. Yang, and L. B. Kong, "Enhanced microwave magnetic and attenuation properties for Z-type barium ferrite composites with flaky fillers," $J$. Appl. Phys., 110063907 (2011).

68. R. C. Pullar, "Hexagonal ferrites: A review of the synthesis, properties and applications of hexaferrite ceramics," Prog. Mater. Sci., 57 1191-1334 (2012).

69. H. Khanduri, M. Chandra Dimri, H. Kooskora, I. Heinmaa, G. Viola, H. Ning, M. J. Reece, J. Krustok, and R. Stern, "Structural, dielectric, magnetic, and nuclear magnetic resonance studies of multiferroic Y-type hexaferrites," J. Appl. Phys., 112073903 (2012).

70. S. H. Mahmood, M. D. Zaqsaw, O. E. Mohsen, A. Awadallah, I. Bsoul, M. Awawdeh, and Q. I. Mohaida, "Modification of the magnetic properties of $\mathrm{Co}_{2} \mathrm{Y}$ hexaferrites by divalent and trivalent metal substitutions," Solid State Phenom., 24193 (2016).

71. K.-S. Moon, Y.-M. Kang, I. Han, and S.-E. Lee, "Grain growth behavior of $\mathrm{Ba}_{1.5} \mathrm{Sr}_{1.5} \mathrm{Co}_{2} \mathrm{Fe}_{24} \mathrm{O}_{41}$ flakes in molten salt synthesis and the magnetic properties of flake/polymer composites," J. Appl. Phys., 120[19] 194102 (2016).

72. J. Jeong, W. Cho, D. W. Hahn, B. C. Moon, and Y. H. Han, "Synthesis of $\mathrm{Co}_{2} \mathrm{Z}$ Ba-ferrites," Mater. Lett., 59 3959-62 (2005).

73. K. N. Rozanova, Z. W. Li, L. F. Chen, and M. Y. Koledintseva, "Microwave permeability of $\mathrm{Co}_{2} \mathrm{Z}$ composites," J. Appl. Phys., 97013905 (2005).

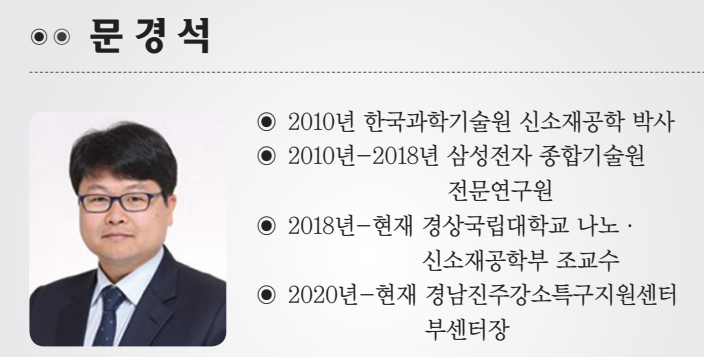

